\title{
LETTER FROM THE EDITOR: THEORIA (2010-2012)
}

Three years have passed since THEORIA joined, in 2010, the Open Journal System, the open access editorial platform, that allowed us to release, under a Creative Commons License, all our issues since January 2003. Google analytics reveals that nearly 50.000 visitors accessed our site between 2010 and 2012: only 23\% of them came from Spain; the United States, Mexico and the United Kingdom ranked $2^{\text {nd }}$ to $4^{\text {th }}$ in number of visits, followed by many other Latin-American and European countries. In terms of authors and reviewers, THEORIA looks international as well: less than one third of the papers published in the last three years were written by Spaniards; only a quarter of our reviewers were Spanish-the United States being at the top of this list. The OJS also provides public statistics of our editorial process: in the same period, we have processed around 60 papers per year, of which $75 \%$ were rejected; on average it took around 45 days to get the reports and make the decision. Our editorial practices were audited and approved by the Spanish Foundation for Science and Technology and we retain our INT2 status at the European Reference Index for the Humanities. All in all, we have made a successful transition to the Open Access regime and we believe our sponsor (Ministry of Education, Universities and Research of the Basque government), authors and reviewers will be happy to know that they are sustaining a quality journal that reaches the biggest possible audience. Our most sincere thanks to all of them.

On behalf of our publisher, the University of the Basque Country, I should also thank our editorial board and I am sure they will share my gratitude to Dr. David Teira, deputy editor of THEORIA during the last three years and the real driving force behind its transformation. David is stepping aside to a consulting role and two new editors will take over for the coming three years (2013-2015). Dr. Cristina Corredor (University of Valladolid) will take responsibility for the areas of logic, philosophy of mind and language. Dr. Valeriano Iranzo (University of Valencia) will be in charge of the areas of history, philosophy and social studies of science. We have great editorial projects for the coming years and I am sure we will all contribute to make THEORIA an even better journal for our readers.

Andoni Ibarra Editor-in-Chief 